\title{
A Meta-analysis of The Prevalence of Depression Among Gay in China
}

\author{
$\mathrm{Xu}$ Chengtao $^{1,{ }^{*}}$ Chen Weizhi ${ }^{2}$ Gao Jinyu ${ }^{3}$ Huang Zhe ${ }^{4}$ \\ ${ }^{\text {I} Q i n g d a o ~ U n i v e r s i t y ~ o f ~ S c i e n c e ~ a n d ~ T e c h n o l o g y ~ L a w ~ S c h o o l, ~ Q i n g d a o, ~ S h a n d o n g, ~ C h i n a ~}$ \\ ${ }^{2}$ Qingdao University of Science and Technology Law School, Qingdao, Shandong, China \\ ${ }^{3}$ Hunan University of Chinese Medicine, Changsha, Hunan, China \\ ${ }^{4}$ Qingdao University of Science and Technology Law School, Qingdao, Shandong, China \\ *Corresponding author.Email:873963773@qq.com
}

\begin{abstract}
Purpose: To understand the prevalence of depression among gay in China through Meta-analysis and to provide a scientific basis for early psychological intervention. Methods: Relevant domestic and foreign literature was searched, and the quality of the included scope was evaluated, and meta-analysis, subgroup analysis and sensitivity analysis were applied to stata15.0. Results: A total of 11 papers with a total sample size of 2901 were included, and the prevalence of depression among gay in China was 36.8\% [95\% confidence interval (CI): $33.1 \%$ to $40.5 \%$ ]. In a subgroup analysis of the depression prevalence profile, the prevalence of depression was higher in high-income areas $(40.1 \%)$ than in low- and middle-income areas (35\%); the prevalence of depression after $2015(40.3 \%)$ was higher than the prevalence before 2015 (34.2\%). All differences were statistically significant $(\mathrm{P}<0.05)$. Sensitivity analyses were conducted to show that the Meta-analysis results for depression prevalence were stable, and the Egger's test and observation of the distribution across studies in the funnel plot indicated a low likelihood of publication bias. Conclusion: For the depression situation of gay in China, appropriate intervention methods should be adopted for early intervention to improve the depression situation of gay.
\end{abstract}

Keywords: Gay community, Depression, Prevalence, Meta-analysis

\section{INTRODUCTION}

Gay are often discriminated and rejected by society, and experience multiple pressures and discrimination from society, family and marriage, and their mental health is relatively poor, often accompanied by severe depression. At present, most domestic scholars have focused on the mental health of MSM and HIV patients, but less attention has been paid to individual groups of gay, so the mental health problems of gay need urgent attention. Meta-analysis was conducted to explore the prevalence of depression in the Chinese gay population and to provide theoretical support for appropriate interventions to improve mental health.

\section{METHODS}

\subsection{Literature Search}

In this paper, CNKI, Wan fang, PubMed, were systematically searched for the Chinese search terms "gay", "sexual minorities" from the time of database construction to December 31, 2020. The Chinese search terms were "gay", "sexual minorities", "mental health", and "depression". The foreign language search terms are "psychological health" OR "mental health" AND "gay" AND "China". The literature search was supplemented by the literature tracing method.

\subsection{Inclusion and exclusion criteria of the literature}

Literature inclusion criteria: (1) The literature study reported the prevalence of easy prevalence or depression among gay, and the sample size. (2) The region of the literature study was mainland China. (3) The literature study clarified the diagnostic criteria or the basis for the diagnosis of depression.

Literature exclusion criteria: (1) The literature study was a qualitative study, literature review, etc. (2) Age $\leq$ 14 years for gay men. (3) The statistical methods of the literature study were not applicable. (4) If there was 
duplicate literature or duplicate data, the data with the largest sample size and most comprehensive results were extracted by two investigators according to the inclusion and exclusion criteria.

\subsection{Data Extraction}

For all included studies in the literature the following data were extracted: first author, year of investigation, study area, sampling method, number of depressed people, sample size, and diagnostic criteria.

\subsection{Literature quality evaluation}

Quality scoring was performed using the criteria of the STROBE statement for cross-sectional studies. A score of 1 was given for each article that met or conformed to the entry, and a score of 0 was given for not meeting the entry, for a total of 22 entries, out of 22 points. A total score of $\leq 11$ was considered low quality, and a total score of $>11$ was considered high quality.

Table 1. Basic information sheet of the literature

\begin{tabular}{|c|c|c|c|c|c|c|}
\hline First author & $\begin{array}{l}\text { Year of } \\
\text { survey }\end{array}$ & Study area & Sampling Method & $\begin{array}{l}\text { Sample } \\
\text { size }\end{array}$ & $\begin{array}{l}\text { Diagnostic } \\
\text { criteria }\end{array}$ & $\begin{array}{l}\text { Quality } \\
\text { evaluation }\end{array}$ \\
\hline Xie Yan ${ }^{[1]}$ & 2015 & Shanghai & $\begin{array}{c}\text { Voluntary Consultation and } \\
\text { Testing Clinic }\end{array}$ & 544 & CES-D & 14 \\
\hline $\begin{array}{c}\text { Huang } \\
\text { Fengrong }^{[2]}\end{array}$ & 2010 & Shanghai & Rolling Snowball & 33 & SDS & 14 \\
\hline Jiang Tingting ${ }^{[3]}$ & 2016 & Zhejiang & $\begin{array}{c}\text { Voluntary Consultation and } \\
\text { Testing Clinic }\end{array}$ & 349 & SDS & 13 \\
\hline Hu Shan ${ }^{[4]}$ & 2016 & $\begin{array}{l}\text { Chongqing } \\
\text { Sichaun }\end{array}$ & $\begin{array}{l}\text { Internet Recruiting } \\
\text { NGO Recruiting }\end{array}$ & 603 & CES-D & 14 \\
\hline Zhou Wei[5] & 2015 & Ningbo & Peer driven & 67 & CES-D & 11 \\
\hline Pan Xuemei[6] & 2016 & Guangdong & $\begin{array}{l}\text { Rolling Snowball } \\
\text { Peer driven }\end{array}$ & 194 & CES-D & 11 \\
\hline Zheng Yingjun ${ }^{[7]}$ & 2005 & Anhui & Convenient sampling & 93 & SDS & 8 \\
\hline Shi Guozheng ${ }^{[8]}$ & 2014 & Shanghai & Convenient sampling & 81 & CES-D & 12 \\
\hline Chen Fang ${ }^{[9]}$ & 2015 & $\begin{array}{c}\text { Guangdong.Chong } \\
\text { qing.Chengdu }\end{array}$ & Rolling Snowball & 439 & CES-D & 8 \\
\hline Luo Xiaomin ${ }^{[10]}$ & 2010 & Foshan & $\begin{array}{c}\text { Voluntary Consultation and } \\
\text { Testing Clinic }\end{array}$ & 78 & SDS & 9 \\
\hline Yu Yong ${ }^{[11]}$ & 2016 & Guangzhou & Peer driven & 420 & SDS & 13 \\
\hline
\end{tabular}




\subsection{Statistical Analysis}

Meta-analysis of the prevalence of depression among gay in China was performed using stata15.0 software, and $\mathrm{Q}($ Significance level $\mathrm{P}<0.10)$ test and $\mathrm{I}^{2}$ (Significance level $\mathrm{I}^{2} \geq 50 \%$ ) statistics were calculated to measure the homogeneity of the studies. If $\mathrm{I}^{2}<50 \%$ and $\mathrm{P}>0.05$, it means that there is less heterogeneity among studies and a fixed-effects model is used, and vice versa, a random-effects model is used. Publication bias was assessed by Egger's test. The stability of the combined prevalence was observed by using different effect models and excluding any of the literature, and if the results did not vary significantly, it suggested that the study results were stable. Subgroup analysis was performed according to geographic region, survey year, diagnostic criteria, and sampling method, and statistically significant if $\mathrm{P}<0.05$.

\section{RESULTS}

\subsection{Basic characteristics of the literature}

Through the literature search, a total of 367 pieces of literature were obtained, and 206 pieces remained after eliminating duplicate literature. 11 pieces of Chinese literature were finally included according to the inclusion and exclusion criteria, and the literature included a total of 2901 study subjects, of which the number of people with depression was 1132 . The basic information of the included literature is shown in Table 1.

\subsection{Depression among gay in China}

A heterogeneity test of the included 11 papers showed some heterogeneity $\left(\mathrm{I}^{2}=73.6 \%, \mathrm{P}<0.05\right)$, so a random-effects model was used, and Meta-analysis revealed that the prevalence of depression among gay men in China was $36.8 \%$ [ $95 \%$ confidence interval (CI): $33.1 \%-40.5 \%]$.

Subgroup analysis: the prevalence of depression was higher in the gay population in high-income areas $(40.1 \%)$ than in low- and middle-income areas (35\%); the prevalence of depression was higher in the post-2015 gay population $(40.3 \%)$ than in the pre-2015(34.2\%). The prevalence of depression was higher in the other sampling methods $(40.8 \%)$ than in the snowball/peer driven (32.3\%) gay cohort. All differences were statistically significant $(\mathrm{P}<0.05)$. The prevalence of depression using the SDS diagnostic criteria $(40.8 \%)$ was higher than the prevalence of CES-D (34.1\%). There was no statistically significant difference in the prevalence of depression in the gay population by diagnostic criteria $(\mathrm{P}>0.05)$, as shown in Table 2.

\subsection{Sensitivity Analysis}

The combined prevalence was $38.6 \%(95 \% \mathrm{CI}$ : $36.8 \%-40.3 \%$ ) using a fixed-effects model and $36.8 \%$ (95\% CI: $32.7 \%-40.8 \%)$ using a random-effects model, with no significant change in the results; the prevalence of depression did not change significantly after exclusion of any of the included papers. The results of the Meta-analysis of depression prevalence were stable.

\subsection{Publication bias}

The egger test method and funnel plot were used to test whether there was publication bias among the studies. Quantitative analysis by the Egger test method showed $\mathrm{t}=-1.51, \mathrm{p}=0.166$, indicating a low possibility of publication bias; observation of the distribution of the studies in the funnel plot also indicated a low possibility of publication bias.

\section{CONCLUSION}

The prevalence of depression in China's gay male population is currently not given much attention. The present meta-analysis on the prevalence of depression in China's gay male population included 11 papers, through which the analysis showed that the prevalence of depression in China's gay male population is $36.8 \%$, which is significantly higher than the prevalence of heterosexual men in China, which may be related to the discrimination they suffer in different environmental contexts due to their sexual orientation, the This may be related to the discrimination, stigmatization, prejudice and misunderstanding they suffer from in different environmental contexts due to their sexual orientation, which shows that poor psychological status directly affects the quality of life of the gay male population in China. 
Table 2.Meta-analysis of depression prevalence in various subgroups of gay in China

\begin{tabular}{|c|c|c|c|c|c|c|c|c|}
\hline Analyze the project & $\begin{array}{l}\text { Number of } \\
\text { literature }\end{array}$ & $\begin{array}{l}\text { Sample } \\
\text { size }\end{array}$ & $\begin{array}{c}\text { Number of } \\
\text { depressed people }\end{array}$ & $\begin{array}{c}\text { Prevalence ( } 95 \% \mathrm{Cl} \\
(\%)\end{array}$ & $\mid{ }^{2}(\%)$ & P-value & H-value & $\begin{array}{c}\text { Egger } \\
\text { test }\end{array}$ \\
\hline \multicolumn{9}{|l|}{ Geographical area } \\
\hline High-income areas & 5 & 1427 & 579 & $40.1(35.3-44.9)$ & $63.60 \%$ & $<0.05$ & 1.659 & 0.718 \\
\hline $\begin{array}{c}\text { Middle/low income } \\
\text { areas }\end{array}$ & 6 & 1474 & 772 & $35(29.8-40.2)$ & $80.10 \%$ & $<0.05$ & 2.24 & 0.145 \\
\hline \multicolumn{9}{|l|}{ Survey era } \\
\hline Before 2015 & 7 & 1335 & 484 & $34.2(29.2-39.2)$ & $64.70 \%$ & $<0.05$ & 1.682 & 0.374 \\
\hline After 2015 & 4 & 1566 & 648 & $40.3(34.1-46.4)$ & $83.90 \%$ & $<0.05$ & 2.491 & 0.121 \\
\hline \multicolumn{9}{|l|}{ Diagnostic criteria } \\
\hline CES-D & 6 & 1928 & 756 & $34.1(28.5-39.8)$ & $83.60 \%$ & $<0.05$ & 2.469 & 0.055 \\
\hline SDS & 5 & 973 & 406 & $40.8(35.6-46.0)$ & $53.80 \%$ & 0.07 & 1.472 & 0.504 \\
\hline \multicolumn{9}{|l|}{ Sampling Method } \\
\hline $\begin{array}{c}\text { Snowballing/peer } \\
\text { push }\end{array}$ & 5 & 1153 & 405 & $32.3(25.8-38.7)$ & $77.70 \%$ & $<0.05$ & 2.119 & 0.339 \\
\hline Other & 6 & 1748 & 727 & $40.8(36.8-44.8)$ & $57.90 \%$ & $<0.05$ & 1.542 & 0.401 \\
\hline
\end{tabular}

In the subgroup analysis, the prevalence of depression was lower in low- and middle-income regions than in high-income regions, where life stress, work pressure and lack of human feelings lead to more severe depressive tendencies in sexual minority groups, as the gay male population has difficulty in receiving more social support and is under more psychological pressure. Different regions have different levels of social support and openness, and different levels of social support and openness directly affect people's psychological health ${ }^{[12]}$. Snowballing or peer-driven surveys limited to a group of people with similar idea attributes can create a significant underrepresentation problem. This is because a group of people with similar views is often identified through the results of mutual referrals. Therefore, different sampling methods may be influenced by the subjective consciousness of the sampled group and have some influence on the analysis results. This study did not find an effect of different diagnostic criteria on the prevalence of depression in the gay population, which may be the result of large differences in sample size between studies and different levels of control for confounding factors and criteria.

The advantage of the present study is that the Meta method was used to analyze the prevalence of depression in the gay male population in China in a comprehensive manner, to fully understand the mental health status of the gay male population in China, and to provide a basis for reasonable interventions for policy makers. In addition to the shortcomings of the Meta-analysis method itself, this study still has two shortcomings.

(1) China is a vast country, and the prevalence of depression in homosexuals varies across geographic and cultural backgrounds, all of which lead to a high degree of heterogeneity, so the conclusions need to be verified 
by more studies.

(2) Different ages, family histories, and life experiences have a great impact on the mental health of gay men, which could not be further analyzed and tested in this paper.

\section{ACKNOWLEDGMENTS}

Mid-term Achievements of "Exploration and Practice of "Four-dimensional One" Talent Cultivation Model for Social Work Majors for the Construction of New Liberal Arts", Cultivation Project of Teaching Achievement Award of Qingdao University of Science and Technology in 2020

\section{REFERENCES}

[1] XIE Yan; LIU Ying; YANG Yong-mei, Analysis on depressive symptoms and related factors of men who have sex with men attending HIV voluntary counseling and testing clinics in Shang hai [J], Chinese Journal of Disease Control \& Prevention, 2018,22(12):1248-1251.

[2] Huang Feng-rong, HUANG Hong, ZHUANG Ming-hua, FANG Hui, LI Sheng-hui, YE Xiu-xia, WANG Jun-li, CHEN Tao, Investigations on social psychology and sexual behavior of 52 male homosexual adolescents in Shanghai[J], Journal of Shanghai Jiaotong University (Medical Science), 2010, 30(05): 581-584.

[3] Jiang Tingting; Pan Xiaohong; Wang Hui; Zhou Xin; Ma Qiaoqin, Depressive, anxiety symptoms and related influential factors among man who have sex with man in Zhejiang[J], Chinese Journal of AIDS \& STD,2016,22(05):357-360+368.

[4] HU Shan; ZHONG Xiao-Ni; WEN Xiao-Yan; HAN Ming-Ming; TAN Ming-Tian; HUANG Ai-Long; PENG Bin, Characteristics of anxiety and depression symptoms among gays and bisexual men with HIV negative[J], Chinese Mental Health Journal, 2016, 30(03): 213-219.

[5] ZHOU Wei; WU Feng; GONG Jing, A study on the status of depressive symptoms and its influencing factors among men who have sex with men[J], Zhejiang Journal of Preventive Medicine, 2015, 27(07): 657-660.

[6] PAN Xue-mei; CHEN Zhen-bo; ZHENG Wen-Juan; HUANG Jin-Mei; DENG You-liang; CHEN Zhuo-tong, Investigation of current status of depression, quality of life and influencing factors among men who have sex with men in Lianzhou [J], Jiangsu Journal of Preventive Medicine, 2016, 27(01): 44-47.
[7] ZHENG Ying-Jun; XU Juan; ZHANG Hong-Bo, Anxiety, Depression and High-risk Behaviors among Men Who Have Sex with Men[J],Chinese Mental Health Journal,2005(10):57-59.

[8] SHI Guo-zheng; YIN Fang-lan; ZHANG Yong, Study on Depression Status and Related Factors among Men who have Sex with Men in Jiading District[J], Chinese Primary Health Care, 2014, 28 (04):65-67.

[9] CHEN Fang; DING Fan; LIN Xiao-Jie; WANG Xiao-Dong; HE Huan; HUANG Wen; DONGYanYan; YANG Qiao-Hong; ZHANG Hong-Bo, Prevalence rates of depression and anxiety in HIV -infected men who have sex with men[J], Chinese Mental Health Journal, 2015,29 (04):251-257.

[10] LUO Xiaomin; LIU Jun; LIANG Zimian; LI Yan; LI Jing; TAN Zhimin; YANG Yi, Depressive symptoms and related factors among men who have sex with men in Foshan[J], Journal of Guangdong Pharmaceutical University, 2018, 34(01): 115-118+123.

[11] Yu Yong; Wu Ting; Li Ya, Gay Men's Gender Roles and Mental Health in Guangzhou, China Journal of Health Psychology[J], [11]2016, 24(11): 1618-1622.

[12] S.attler FA, Ulrich W, Hanna C. Effects of Minority Stress, Group Level Coping, and Social Support on Mental Health of German Gay Men[J]. PLoS One, 2016,11(3): e0150562. 